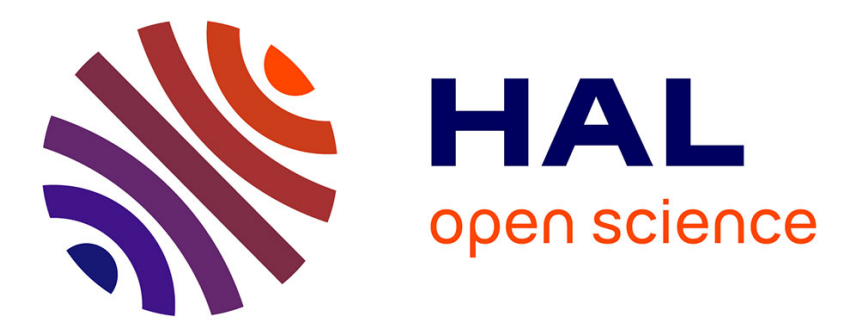

\title{
Taking advantage of pathogen diversity and immune priming to minimize disease prevalence in host mixtures: a model
}

Pauline Clin, Frédéric Grognard, Ludovic Mailleret, Florence Val, Didier Andrivon, Frédéric Marie Hamelin

\section{To cite this version:}

Pauline Clin, Frédéric Grognard, Ludovic Mailleret, Florence Val, Didier Andrivon, et al.. Taking advantage of pathogen diversity and immune priming to minimize disease prevalence in host mixtures: a model. Phytopathology, 2021, 111 (7), pp.1219-1227. 10.1094/PHYTO-09-20-0429-R . hal-03124229

\author{
HAL Id: hal-03124229 \\ https://hal.science/hal-03124229
}

Submitted on 28 Jan 2021

HAL is a multi-disciplinary open access archive for the deposit and dissemination of scientific research documents, whether they are published or not. The documents may come from teaching and research institutions in France or abroad, or from public or private research centers.
L'archive ouverte pluridisciplinaire HAL, est destinée au dépôt et à la diffusion de documents scientifiques de niveau recherche, publiés ou non, émanant des établissements d'enseignement et de recherche français ou étrangers, des laboratoires publics ou privés. 


\section{Taking advantage of pathogen}

diversity and immune priming to minimize disease prevalence in host mixtures: a model

5 Pauline Clin ${ }^{1,2}$, Frédéric Grognard ${ }^{3}$, Ludovic Mailleret ${ }^{2,3}$, Florence Val ${ }^{1}$, Didier 6 Andrivon ${ }^{1}$, Frédéric M. Hamelin ${ }^{1, *}$

${ }^{1}$ IGEPP, INRAE, Institut Agro, Univ Rennes, 35000, Rennes, France; ${ }^{2}$ Université Côte d'Azur, INRAE, CNRS, ISA, France; ${ }^{3}$ Université Côte d'Azur, Inria, INRAE, CNRS, Sorbonne Université, Biocore, France

* Corresponding author: frederic.hamelin@agrocampus-ouest. fr

Abstract Host mixtures are a promising method for agroecological plant disease control. Plant immunity is key to the success of host mixtures against polymorphic pathogen populations. This results from priming-induced cross-protection, whereby plants able to resist infection by specific pathogen genotypes become more resistant to other pathogen genotypes. Strikingly, this phenomenon was thus far absent from mathematical models aiming at designing host mixtures. We developed a model to specifically explore how priming affects the coexistence of two pathogen genotypes in host mixtures composed of two host genotypes, and how it impacts disease prevalence. The main effect of priming is to reduce the coexistence region in the parameter space (due to cross protection), and to generate a singular mixture of resistant/susceptible hosts corresponding to the maximal reduction disease prevalence (in absence of priming, a resistant pure stand is optimal). The epidemiological advantage of host mixtures over a resistant pure stand thus appears as a direct consequence of immune priming. We also showed that there is indirect cross-protection between host genotypes in a mixture. Moreover, the optimal mix prevents the emergence of a resistance-breaking pathogen genotype. Our results highlight the importance of considering immune priming to design optimal and sustainable host mixtures.

Keywords: cultivar mixtures, gene-for-gene, virulence, avirulent, polymorphism, induced resistance, systemic acquired resistance, priming 


\section{Introduction}

Growing awareness of the negative impacts of pesticides on biodiversity and human health is increasingly driving the development of more sustainable methods to control plant diseases (Matthews, 2015). Until now, the main alternative to using pesticides against plant pathogens has been to breed genetically resistant plant varieties or cultivars and deploy them as pure stands (Wolfe and Ceccarelli, 2020). Under these conditions, pathogen populations often evolve and break down resistance genes after a few years, while a breeding program may require a least a decade (Brown, 2015; Zhan et al., 2015). More lasting control methods will require managing genetic resistances in time (Bargués-Ribera and Gokhale, 2020; Nilusmas et al., 2020), and/or in space (Fabre et al., 2012, 2015; Djidjou-Demasse et al., 2017; Papaïx et al., 2018; Rimbaud et al., 2018b,a; Rousseau et al., 2019; Watkinson-Powell et al., 2019; Burdon et al., 2020).

Host mixtures are one of the possible methods to achieve host diversification in space. They consist in growing several varieties of the same plant species in the same field and at the same time (Wolfe, 1985; Mundt, 2002). Host mixtures are or have been used against plant pathogens in various regions of the world, including Asia, Europe and North America (Finckh et al., 2000; Zhu et al., 2000; Mundt, 2002; Han et al., 2016; Reiss and Drinkwater, 2018). In the Yunnan province of China, a large-scale experiment on rice blast was carried out over two years with thousands of farmers (Zhu et al., 2000). Disease-susceptible rice varieties were planted in twocomponent mixtures with resistant varieties. The effectiveness was such that the fungicide treatments could be stopped in the following year. The overall prevalence (more specifically the percentage of rice stems that were showing symptoms) was reduced by $94 \%$ compared to pure stands. Although host mixtures have long been studied both theoretically (Kampmeijer and Zadoks, 1977; Jeger et al., 1981a; Ohtsuki and Sasaki, 2006) and experimentally (Jeger et al., 1981b; Wolfe, 1985; Zhu et al., 2000; Ben M'Barek et al., 2020), their design remains to be optimized to be more widely and efficiently used (Mikaberidze et al., 2015).

Host mixtures are often composed of resistant and susceptible plants in which resistance is qualitative, meaning that infection either succeeds or fails (as opposed to quantitative resistance, which only partially decreases the success of infection). 
The majority of studies of mixtures of quantitatively resistant host genotypes have shown relatively low levels of disease control (Mundt, 2002). By contrast, the Yunnan large-scale experiment mixed qualitatively resistant and susceptible varieties (Zhu et al., 2000). Qualitative resistance is often conferred by major resistance genes and driven by gene-for-gene interactions (Flor, 1971; Milgroom, 2015). Pathogen genotypes can then be classified into two types: the resistance-breaking (virulent) type, which can successfully infect both resistant and susceptible hosts, and the wild (avirulent) type, which can successfully infect susceptible hosts only. In biotrophic pathogens (those feeding on living host tissues), an interaction between a wild-type pathogen and a resistant genotype generally triggers a hypersensitive response: the plant blocks the infection process by killing its own cells around the point of infection.

Such a strong defense response may result in the plant being primed against future infections. Immune priming is defined as increased defense to pathogen infections following previous exposure to a pathogen or an elicitor (Tidbury et al., 2012). In the plant disease epidemiology literature, and in particular in host mixtures with gene-for-gene interactions, priming corresponds to the elicitation of specific defense responses which can lead to “induced resistance" (Lannou et al., 1995; Tellier and Brown, 2008). These defense responses include in particular the Systemic Acquired Resistance (SAR) (Vallad and Goodman, 2004; Walters et al., 2005; Conrath, 2011; Pastor et al., 2013). SAR is systematically induced when the aerial tissues of resistant plants are tentatively infected by a wild-type biotrophic pathogen (Ross, 1961; Vlot et al., 2008). This defense mechanism involves the activation of signaling pathways (usually the salicylic acid pathway in the case of biotrophic pathogen infections; Pastor et al. (2013)), allowing SAR to be triggered and active in the entire plant (Cameron et al., 1999; Mishina and Zeier, 2007). SAR effects are long-lasting, and confer partial resistance against subsequent attacks by a broad spectrum of pathogens, including viruses, bacteria, and fungi (Verberne et al., 2000; Durrant and Dong, 2004; Mishina and Zeier, 2007). From now on, for the sake of generality and to avoid confusion with constitutive resistance mechanisms, we will use the term "priming" to denote "induced resistance".

The epidemiological effectiveness of mixtures of resistant and susceptible plants can be explained by three main mechanisms (Wolfe, 1985; Mikaberidze et al., 2015): 
(i) dilution of susceptible hosts in space, (ii) interception of pathogen transmission forms by resistant hosts (so-called "barrier effect"), and (iii) priming of resistant hosts by wild-type pathogen genotypes. For instance, in the Yunnan large-scale experiment, the prevalence was reduced from $20 \%$ to $1 \%$ on susceptible varieties in mixtures compared to pure stands. This suggests that resistant varieties indirectly protected susceptible varieties at the population scale, as expected from dilution and barrier effects. More surprisingly, the prevalence on resistant varieties significantly decreased from $2.3 \%$ to $1 \%$ in mixtures compared to pure stands. This means that susceptible varieties somehow protected resistant varieties, which may be due to a priming effect (Zhu et al., 2000). From a broader perspective, priming is considered as a key to the success of host mixtures. This is because the wild-type pathogen produces little or no symptoms on resistant hosts but triggers a long-lasting immune response protecting against subsequent infections from other pathogen genotypes (Lannou et al., 1995; Calonnec et al., 1996). However, priming was thus far mostly absent from mathematical models aiming at designing host mixtures.

This theoretical study aims at exploring the impact of priming on the efficiency of host mixtures against plant diseases. By means of mathematical analyses of a parsimonious model, we analyzed under which conditions the wild-type and resistancebreaking pathogen genotypes can coexist, and whether we can take advantage of pathogen diversity and priming to minimize disease prevalence. In particular, we explored whether susceptible hosts indirectly protect resistant hosts in a mixture, as experimentally observed (Chin and Wolfe, 1984; Zhu et al., 2000), and to what extent this effect is related to immune priming.

\section{Modelling}

We consider a mixture of susceptible and resistant plant hosts. Note that in plant pathology, the term "susceptible" means the opposite of resistant. We will stick to this terminology and we will refer to "uninfected" plants when it comes to epidemiology. However, uninfected plants will be denoted as $S$, in accordance with the reference SIR model in epidemiology. We will consider a continuous-time model with continuous planting and replanting best adapted to perennial crops in tropical re- 
gions (Madden et al., 2007). More specifically, we consider that the host is present yearlong and we ignore seasonality in climatic conditions for simplicity. This will allow us to identify the general mechanisms promoting the success (or failure) of host mixtures, which are expected to hold in annual crops as well.

We define as $0 \leq p \leq 1$ the proportion of resistant hosts in the mixture; $1-p$ is the proportion of susceptible hosts. As we are interested in epidemiological dynamics in an agricultural context, $p$ is assumed to be a constant. This parameter is a control variable in the hands of the grower.

We assume the resistance-breaking (RB) pathogen genotype incurs a cost which reduces its transmission rate by a factor $0 \leq c \leq 1$ relative to the wild-type (WT). The idea of a cost as a counterpart to the ability of breaking a resistance gene originated as a theoretical hypothesis to explain the often observed maintenance of polymorphism in pathogen populations, in both agricultural and wild ecosystems (Vanderplank, 1968; Sasaki, 2000; Gandon et al., 2002; Tellier and Brown, 2007; Brown, 2015). Since then, such a cost has been demonstrated and measured in a number of parasites, including bacteria (Cruz et al., 2000; Wichmann and Bergelson, 2004), fungi (Carson, 1998; Thrall and Burdon, 2003; Bahri et al., 2009; Huang et al., 2010; Caffier et al., 2010; Bruns et al., 2014; Bousset et al., 2018), viruses (Jenner et al., 2002; Janzac et al., 2010; Fraile et al., 2010; Poulicard et al., 2010; Ishibashi et al., 2012; Khatabi et al., 2013), nematodes (Castagnone-Sereno et al., 2007) and oomycetes (Montarry et al., 2010).

We assume that priming reduces the probability that a resistant host is infected by a RB genotype by a factor $0 \leq \rho \leq 1$ (priming effect). Priming is effective relatively rapidly: a few days after pathogen inoculation in experiments (Ross, 1961; Maleck et al., 2000). Note that priming can be fully effective (Kuć, 1982). In such a case $(\rho=1)$, the RB genotype cannot infect the primed resistant hosts as long as priming is active.

The rate at which priming loses its effectiveness is $\gamma$. It corresponds to the inverse of the mean time during which priming is effective. Several studies have shown that SAR can last for several weeks. The original one (Ross, 1961) estimates that it persists for 20 days, but more recent reports show that it can last for weeks to months (Kuć, 1982; Fu and Dong, 2013). 
We assume that infected hosts remain infectious until harvest, as is the case for most plant viruses and many other parasites. The rate at which a host is replaced with an uninfected one (due to harvesting and replanting) is $\alpha$. It corresponds to the inverse of the length of the growing period.

We assume that the total host density $N$ is constant. Since the proportion of resistant hosts is $p$, the total density of resistant host is $N_{r}=p N$, and the total density of susceptible hosts is $N_{s}=(1-p) N$. The density of uninfected susceptible host is $S_{s}$. The density of uninfected resistant host is $S_{r}$. The density of resistant host primed by the WT is $S_{r}^{*}$. Priming makes resistant hosts partially immune to the RB genotype until its effect vanishes (Fig. 1). The density of susceptible hosts infected by the WT is $I_{s}$. The densities of susceptible and resistant hosts infected by the RB genotype are $J_{s}$ and $J_{r}$, respectively. Although susceptible plants may be co-infected by the WT and the RB genotype, we do not allow for coinfections for simplicity. We have $S_{S}=N_{S}-I_{S}-J_{S}$, and $S_{r}=N_{r}-S_{r}^{*}-J_{r}$. The transmission rate of the WT is $\beta$. The forces of infection of the WT and RB genotypes are therefore, respectively: $F=\beta I_{S}$, and $G=(1-c) \beta\left(J_{s}+J_{r}\right)$. The model is formulated as a system of ordinary differential equations, in which the dot denotes differentiation with respect to time $t$ :

$$
\begin{aligned}
\dot{I}_{s} & =F S_{s}-\alpha I_{s}, \\
\dot{S}_{r}^{*} & =F S_{r}-(1-\rho) G S_{r}^{*}-(\gamma+\alpha) S_{r}^{*}, \\
j_{s} & =G S_{s}-\alpha J_{s} \\
j_{r} & =G S_{r}+(1-\rho) G S_{r}^{*}-\alpha J_{r} .
\end{aligned}
$$

We re-scale variables and parameters according to

$$
x=\frac{I_{s}}{N}, \quad m=\frac{S_{r}^{*}}{N}, \quad y=\frac{J_{s}}{N}, \quad z=\frac{J_{r}}{N}, \quad t^{*}=\alpha t, \quad R=\frac{\beta N}{\alpha}, \quad v=\frac{\gamma+\alpha}{\alpha} \geq 1
$$

Biologically, the parameter $R$ corresponds to a basic reproduction number (Madden et al., 2007). This is the mean number of secondary infections produced by a pathogen able to infect $N$ hosts with transmission rate $\beta$ during an average time $1 / \alpha$. From now on, we assume $R>1$, otherwise the pathogen would go extinct.

We define the total prevalence of the disease as the proportion of infected hosts in the plant population: $P=\left(I_{s}+J_{s}+J_{r}\right) / N=x+y+z$. The prevalences of the WT and 
RB genotypes are defined as $P_{w}=I_{s} / N=x$ and $P_{b}=\left(U_{s}+J_{r}\right) / N=y+z$, respectively. In addition, we define the total prevalences in susceptible and resistant host subpopulations as $P_{s}=\left(I_{s}+J_{s}\right) / N_{s}=(x+y) /(1-p)$, and $P_{r}=J_{r} / N_{r}=z / p$, respectively. Lastly, we define the Area Under Disease Progress Curve (AUDPC) as:

$$
A_{U D P C}(t)=\int_{0}^{t} P(\tau) \mathrm{d} \tau
$$

The AUDPC is a standard metric to summarize the epidemic size at time $t$ as it takes into account the speed at which the epidemic spread from time zero to time $t$ (Madden et al., 2007).

Model (1) can be formulated in dimensionless form, where the prime denotes differentiation with respect to $t^{*}$ :

$$
\begin{aligned}
x^{\prime} & =R x[(1-p)-x-y]-x \\
m^{\prime} & =R x(p-m-z)-(1-\rho)(1-c) R(y+z) m-v m, \\
y^{\prime} & =(1-c) R(y+z)[(1-p)-x-y]-y, \\
z^{\prime} & =(1-c) R(y+z)(p-m-z)+(1-\rho)(1-c) R(y+z) m-z .
\end{aligned}
$$

Model (3) has four biologically possible equilibria:

- $(0,0,0,0)$ : the disease (pathogen)-free equilibrium. The prevalence is $P=0$.

- $(\hat{x}, \hat{m}, 0,0)$ : the WT-only equilibrium, which is biologically possible if and only if $R(1-p)>1$. The associated prevalence is $P_{W E}=(1-p)-1 / R$.

- $(0,0, \hat{y}, \hat{z})$ : the RB-only equilibrium, which is biologically possible if and only if $R(1-c)>1$. The associated prevalence is $P_{R B}=1-1 /[R(1-c)]$.

- The coexistence equilibrium $(\bar{x}, \bar{m}, \bar{y}, \bar{z})$ is biologically possible if and only if

$$
\left\{c>p \text { and } p(1-c) R-c>0 \text { and } \rho<\frac{[p(1-c) R-c][(1-p) R+v-1]}{[R(1-p)-1](1-c) R p}\right\}
$$

see Supplementary Information (Section S2).

Biologically, $R(1-p)$ and $R(1-c)$ are the basic reproduction numbers of the WT and RB genotypes, respectively. The above set of conditions implies $R(1-p)>1$ 
and $R(1-c)>1$, meaning that for the coexistence equilibrium to be biologically possible, both the WT and the RB genotypes must be able to invade when alone. The associated prevalence is

$$
P_{C E}=\frac{[(1-p) R+\nu-1][(1-c) R-1]-\rho(1-c) R[R(1-p)-1]}{(1-c) R[(1-\rho)(1-p) R+v-1]}
$$

\section{Results}

Conditions for polymorphism persistence in the pathogen population. Fig. 2 shows the outcome of the competition for susceptible hosts between the WT and the RB genotype in the parameter space $(p, c)$, for representative values of $R, \rho$ and $v$ (see Fig. S1 for additional parameter sets). The polymorphism region is delimited by the conditions (4) of biological feasibility of the coexistence equilibrium. In that region, we proved (Supplementary Section S4) that the coexistence equilibrium is globally asymptotically stable, meaning that the dynamics converge to this equilibrium regardless the initial conditions. This implies that complex dynamics such as cycles or chaos cannot occur in this model. Therefore, polymorphism is stable in the pathogen population. Both the WT and the RB genotype can persist without excluding each other, although they compete for susceptible hosts.

\section{Disease prevalence as a function of the proportion of resistant hosts} and priming. In Figure $3 \mathrm{~B}, p^{\star}$ is a threshold value separating the WT-only region from the coexistence (middle) region (i.e., the solution of $P_{C E}=P_{W T}$ ). For $p<p^{\star}$, the WT competitively excludes the RB genotype (Fig. 2). In this region, the prevalence $\left(P_{W T}=1-p-1 / R\right)$ decreases linearly with respect to $p$. For $p>c$, the RB genotype competitively excludes the WT (Fig. 2). Since susceptible and resistant hosts are equally susceptible to the RB genotype in the RB-only region, the disease prevalence in the latter region is a constant $\left(P_{R B}=1-1 /[R(1-c)]\right)$ whenever $c<p<1$.

In the absence of priming (specific case $\rho=0$, dashed line), the prevalence in the coexistence (middle) region is equal to the prevalence in the RB-only region (i.e. $\left.P_{C E}=P_{R B}\right)$. If $\rho=0$, we define $\hat{p}=c /[R(1-c)]$ such that $P_{W T}=P_{C E}=P_{R B}$. The WT and the RB genotypes actually coexist for all $p \in(\hat{p}, c)$. In the absence of priming, susceptible and resistant hosts are equally susceptible from the RB genotype per- 
spective (in the coexistence and RB-only regions). Consequently, the growth rate of the RB genotype only depends on available hosts $(1-P)$, regardless of whether the WT persists or not. This is why the equilibrium prevalence $(P)$ is a constant in the regions where the RB genotype persists.

Taking priming into account ( $\rho>0$, solid line), the coexistence interval is reduced as the WT outcompetes the RB genotype for all $p \in\left(\hat{p}, p^{\star}\right)$. In the WT-only region, the prevalence decreases down to $p^{\star}$. In the adjacent coexistence region, the prevalence increases up to that in the RB-only region. The prevalence is then not a constant in the coexistence region, since uninfected and primed hosts are not equally susceptible from the RB genotype perspective and their equilibrium ratio depends on the proportion of resistant plants $p$.

As a result, priming (solid line) generates an optimal intermediate proportion of resistant host $p^{\star}$ that minimizes the disease prevalence $P$. In the absence of priming (dashed line), any $p \in(\hat{p}, 1)$ minimizes the prevalence, meaning that host mixtures will not perform better than a pure stand of resistant hosts. The existence of an optimal host mixture is therefore a direct consequence of priming. Note that for a $p$ just below $p^{\star}$, the RB genotype cannot invade. Decreasing $R$ and/or increasing $\rho$ increases the optimal proportion $p^{\star}$, which is a critical threshold to prevent the RB genotype emergence (supplementary Section S1).

\section{Transient dynamics and optimal mixtures in terms of both prevalence} and AUDPC. Figure 4 shows the prevalence $P$ and the Area Under Disease Progress Curve $\left(A_{U D P C}\right)$ over time as a function of the proportion of resistant hosts $p$, with and without priming. Initially ( $0 \leq t \leq 3$ growing periods in Fig. 4 the prevalence and AUDPC are the same regardless whether priming occurs $(\rho>0)$ or not $(\rho=$ 0 ). In both cases, the optimal strategy (minimizing both $P$ and $A_{U D P C}$ ) is to use resistant hosts only $(p=1)$. This is because in the initial phase of the epidemic, the probability that a RB genotype enters into contact with a primed host is very small. Mathematically, this translates into the largest eigenvalue of the linearized system evaluated at disease-free equilibrium being independent of parameters associated with priming ( $\rho$ and $\nu$ ), see supplementary section S2.3.1. After this initial phase ( $t>$ 3 growing periods in Fig. 4), the prevalence of the disease becomes sufficiently large for priming to have a significant effect on the epidemiological dynamics. Therefore, 
the optimal strategy is to mix resistant and susceptible hosts. The optimal mixture is approximately the same in terms of both prevalence and AUDPC. As time goes on, the optimal mix converges towards $p^{\star}$ (the optimal proportion of resistant plants at equilibrium). Overall, these numerical explorations show that our results hold well before reaching equilibrium, provided the epidemiological dynamics have passed an initial phase.

Protection of resistant hosts in the mixture by priming. Figure 5 shows the cumulated prevalences in susceptible and resistant hosts $\left(P_{s}\right.$ and $\left.P_{r}\right)$ as a function of the proportion of resistant hosts $p$, with and without priming.

Let us start by considering the case with no priming $(\rho=0)$. Starting from the RB-edge of the coexistence region and decreasing $p$ decreases the prevalence of the RB genotype $P_{b}$ (Fig. 5A). This is because the RB genotype actually competes with the WT for susceptible hosts but incurs a cost. As a result, the total prevalence in the resistant host $\left(P_{r}\right)$ decreases as well (Fig. 5A). Therefore, there is indirect protection of resistant hosts by susceptible hosts in the coexistence region. Since resistant hosts indirectly protect susceptible hosts by being unavailable for the WT, there is then indirect cross-protection between susceptible and resistant hosts.

Taking priming into account $(\rho>0)$ does not change the prevalence in the susceptible host $P_{s}$ (Fig. 5B). By contrast, the slope of $P_{r}$ is steeper and occurs on a narrower interval, corresponding to a smaller coexistence region. That happens because presence of the WT leads to a certain proportion of the resistant population to be primed and hence less conducive to the RB genotype. By priming, the WT can decrease host availability of the RB genotype and outcompete it. Therefore, the WT outcompetes the RB genotype faster with the help of priming as $p$ is decreased, which creates a narrower coexistence region. Likewise, the prevalences of the WT $\left(P_{w}\right)$ and of the RB genotype $\left(P_{b}\right)$ are qualitatively the same as in the case with no priming, even though their slopes are steeper in the smaller coexistence region (Fig. 3B). Overall, priming has no qualitative effect on the prevalences in resistant and susceptible hosts. Host mixtures generally decrease the prevalences in susceptible and resistant hosts compared to pure stands ( $p=0$ and $p=1$, resp.), regardless of whether priming occurs or not. Quantitatively however, priming exacerbates the effect of mixtures regarding the prevalence in resistant hosts as the 
decrease is sharper than in the absence of priming.

\section{Discussion}

Developing new or preexisting methods based on bio-diversification forms the basics of agroecology (Altieri, 2018); host mixtures are one of these. Indeed, mixtures involving at least one host with gene-for-gene resistance have shown a strong ability to decrease disease prevalence compared to pure stands (Garrett and Mundt, 1999) and are a promising alternative to the unstable dynamics commonly observed in gene for gene systems (the famous "boom and bust" cycles; Wolfe (1985)).

Our study not only confirmed the theoretical effectiveness of genetic host mixtures against plant diseases, but allowed us to clearly disentangle the role of priming in this performance. In particular, we showed that the time during which priming is effective is a key parameter for mixture performance (Fig. S1F and Section S1). However, few references document its value. Our study encourages experiments designed to uncover priming duration in a variety of pathosystems. A key feature of our model is that the epidemiological dynamics necessarily converges to an equilibrium state (Supplementary Section S4). As a corollary, complex dynamics such as cycles or chaos are impossible in our plant epidemic model with immune priming. This observation contrasts with a previous study reporting cycles in an animal epidemic model with immune priming (Tidbury et al., 2012). From an epidemiological standpoint, immune priming in animals is comparable to immune priming in plants. Tidbury et al. (2012) considered a Susceptible-Primed-Infected model, and showed that cycles can occur if and only if infected hosts bear fecundity costs. Priming does not promote cycles unless host population dynamics are taken into account, which is consistent with our agricultural model, where we observed a globally stable equilibrium in a fixed host population. We showed that disease prevalence at equilibrium was minimized for an intermediate proportion of resistant hosts, which highlights the benefits that can be made by promoting host diversity over growing pure stands of either susceptible or resistant hosts. This proportion depends upon the cost of resistance-breaking, but also on the effectiveness of priming.

Moreover, the optimal proportion of resistant plants is also a critical threshold to 
prevent the emergence of the resistance-breaking pathogen genotype, and hence resistance breakdown. Growing resistant varieties as pure stands increases the selection pressure on pathogen populations and thereby promotes the emergence of resistance-breaking pathogen genotypes. Once resistance is broken, the resistancebreaking pathogen genotype may invade and even outcompete the WT, (e.g. Flor, 1971; Wolfe, 1985). To control the associated epidemics, breeders then select for new resistance genes and the cycle repeats until the genetic resource is depleted. This "boom and bust" cycle is thus often referred to as an "arms race" co-evolutionary pattern (Tellier and Brown, 2007). By decreasing the disease prevalence on the resistant component of the mixture, priming should actually protect resistant hosts during the epidemic, and increase the durability of the resistance gene. Unfortunately, there is at the moment little experimental evidence to confirm this theoretical prediction, as few large scale experiments exist (Finckh et al., 2000), and fewer still with pathogen genotypic data. The stability of polymorphism is a central issue in host-parasite coevolution (Hamilton et al., 1990). It has been mainly addressed with population genetics models (Brown and Tellier, 2011), which focus on the frequencies of alleles in the host and parasite populations. Stable polymorphism requires negative direct frequency dependent selection (ndFDS), meaning that the frequency of an allele affects its own fitness (Tellier and Brown, 2007). A mechanism promoting ndFDS is intraspecific competition, namely negative density-dependence. In population genetics models, density-dependence is not considered explicitly. Models combining epidemiology (i.e. demography) and population genetics checked the stability of polymorphism by numerical simulations (Gandon et al., 2002; Tellier and Brown, 2009; Zivković et al., 2019). Although our model addressed polymorphism in the pathogen population only, its stability was demonstrated mathematically. Consistently with a previous study (Tellier and Brown, 2008), priming indeed promotes the fixation of the wild-type and narrows the parameter range for coexistence.

We also showed that susceptible hosts indirectly protect resistant hosts, which was less expected than the opposite effect. In the Yunnan province large-scale experiment (Zhu et al., 2000), the disease prevalence in resistant varieties significantly and unexpectedly decreased in mixtures compared to pure stands. Disease reduction on resistant hosts was interpreted as a possible effect of priming (Zhu et al., 
2000). Our study confirmed the potential effect of priming but also showed that priming is not necessary to explain this observation. The key point is that competition between the wild-type and the resistance-breaking genotype for susceptible hosts generates apparent cross-protection between resistant and susceptible hosts. This is because increasing the density of susceptible hosts promotes the wild-type, which outcompetes the RB genotype on susceptible hosts and in that way protects resistant hosts. Therefore, although resistant hosts are protected by susceptible hosts even in the absence of priming, priming exacerbates indirect cross-protection.

The multiple effects of priming show that priming (provided it occurs) has the potential to significantly improve mixture performance. The fact that priming is more likely in gene-for-gene systems (implying a hyper-sensitive response) than in quantitatively resistant cultivars may explain why most mixtures and multilines are designed with resistant components possessing major, race-specific resistance. However, priming also occurs in cultivars with quantitative resistance, and may explain in part why mixtures involving this type of resistance also work (Andrivon et al., 2003). As a first step towards understanding the combined effects of genetic resistance and immune priming against plant diseases, we assumed a two-component mixture of a susceptible and a resistant host. Future research may consider a larger number of components in the mixture (Mikaberidze et al., 2015). To begin with, a mixture of two distinct resistance genes with two single-resistance-breaking pathogen genotypes could be considered. This way, priming would occur in two directions (both host genotypes could be primed) and it is likely that the benefits in terms of prevalence would be even greater. Although the presence of an additional pathogen genotype capable of breaking both resistances (a "super-race") might challenge this optimistic view (Groth, 1976; Lannou and Mundt, 1997; Carson, 2009), both simulation and experimental evidence suggest that this risk might actually be limited (Barrett and Wolfe, 1978; Lannou et al., 2005; Xu, 2012) and strongly depends on resistance-breaking costs, i.e. relative fitness penalties on non-resistant hosts. Since priming actually reduces the fitness advantage of resistance breaking by decreasing the performance of these pathogen genotypes on the resistant host, it is expected to decrease the risk of emergence of such super races in complex mixtures. Exploring the stochastic emergence of resistant-breaking genotypes (Bourget et al., 2013; 
Chabas et al., 2018) would offer additional insights into the sustainability of host mixtures in agriculture.

Acknowledgments. PC is supported by a Ph.D. fellowship from the INRAE "Plant Health and the Environment" Division and the Council of Brittany Region. FH acknowledges funding from the INRAE "Plant Health and the Environment" Division. The authors thank the reviewers for their helpful suggestions.

Authors' contributions. FG, FH, FV, and PC planned and designed the research. FG, FH, LM, and PC built the model and performed its mathematical analysis. DA, $\mathrm{FH}$, and $\mathrm{PC}$ wrote the manuscript.

\section{References}

Altieri, M. A. (2018). Agroecology: the science of sustainable agriculture. CRC Press. Andrivon, D., Lucas, J.-M., and Ellisseche, D. (2003). Development of natural late blight epidemics in pure and mixed plots of potato cultivars with different levels of partial resistance. Plant Pathology, 52(5):586-594.

Bahri, B., Kaltz, O., Leconte, M., de Vallavieille-Pope, C., and Enjalbert, J. (2009). Tracking costs of virulence in natural populations of the wheat pathogen, Puccinia striiformis f. sp. tritici. BMC Evolutionary Biology, 9(1):26.

Bargués-Ribera, M. and Gokhale, C. S. (2020). Eco-evolutionary agriculture: Host-pathogen dynamics in crop rotations. PLOS computational biology, 16(1):e1007546.

Barrett, J. and Wolfe, M. (1978). Multilines and super-races-a reply. Phytopathology, 68:1535-1537.

Ben M'Barek, S., Karisto, P., Abdedayem, W., Laribi, M., Fakhfakh, M., Kouki, H., Mikaberidze, A., and Yahyaoui, A. (2020). Improved control of Septoria tritici blotch in durum wheat using cultivar mixtures. Plant Pathology. In Press.

Bourget, R., Chaumont, L., and Sapoukhina, N. (2013). Timing of pathogen adaptation to a multicomponent treatment. PLoS One, 8(8):e71926. 
Bousset, L., Sprague, S. J., Thrall, P. H., and Barrett, L. G. (2018). Spatio-temporal connectivity and host resistance influence evolutionary and epidemiological dynamics of the canola pathogen Leptosphaeria maculans. Evolutionary applications, 11(8):1354-1370.

Brown, J. K. (2015). Durable resistance of crops to disease: a Darwinian perspective. Annual review of phytopathology, 53:513-539.

Brown, J. K. and Tellier, A. (2011). Plant-parasite coevolution: bridging the gap between genetics and ecology. Annual review of phytopathology, 49:345-367.

Bruns, E., Carson, M. L., and May, G. (2014). The jack of all trades is master of none: A pathogen's ability to infect a greater number of host genotypes comes at a cost of delayed reproduction. Evolution, 68(9):2453-2466.

Burdon, J. J., Barrett, L. G., Yang, L.-N., He, D.-C., and Zhan, J. (2020). Maximizing world food production through disease control. BioScience, 70(2):126-128.

Caffier, V., Didelot, F., Pumo, B., Causeur, D., Durel, C., and Parisi, L. (2010). Aggressiveness of eight Venturia inaequalis isolates virulent or avirulent to the major resistance gene Rvi6 on a non-Rvi6 apple cultivar. Plant pathology, 59(6):10721080.

Calonnec, A., Goyeau, H., and de Vallavieille-Pope, C. (1996). Effects of induced resistance on infection efficiency and sporulation of Puccinia striiformis on seedlings in varietal mixtures and on field epidemics in pure stands. European Journal of Plant Pathology, 102(8):733-741.

Cameron, R. K., Paiva, N. L., Lamb, C. J., and Dixon, R. A. (1999). Accumulation of salicylic acid and PR-1 gene transcripts in relation to the systemic acquired resistance (SAR) response induced by Pseudomonas syringae pv. tomato in Arabidopsis. Physiological and Molecular Plant Pathology, 55(2):121-130.

Carson, M. (1998). Aggressiveness and perennation of isolates of Cochliobolus heterostrophus from North Carolina. Plant Disease, 82(9):1043-1047.

Carson, M. L. (2009). Crown rust development and selection for virulence in Puccinia coronata f. sp. avenae in an oat multiline cultivar. Plant disease, 93(4):347-353. 
Castagnone-Sereno, P., Bongiovanni, M., and Wajnberg, E. (2007). Selection and parasite evolution: a reproductive fitness cost associated with virulence in the parthenogenetic nematode Meloidogyne incognita. Evolutionary Ecology, 21(2):259-270.

Chabas, H., Lion, S., Nicot, A., Meaden, S., van Houte, S., Moineau, S., Wahl, L. M., Westra, E. R., and Gandon, S. (2018). Evolutionary emergence of infectious diseases in heterogeneous host populations. PLoS biology, 16(9):e2006738.

Chin, K. and Wolfe, M. (1984). The spread of Erysiphe graminis f. sp. hordei in mixtures of barley varieties. Plant Pathology, 33(1):89-100.

Conrath, U. (2011). Molecular aspects of defence priming. Trends in plant science, 16(10):524-531.

Cruz, C. M. V., Bai, J., Oña, I., Leung, H., Nelson, R. J., Mew, T.-W., and Leach, J. E. (2000). Predicting durability of a disease resistance gene based on an assessment of the fitness loss and epidemiological consequences of avirulence gene mutation. Proceedings of the National Academy of Sciences, 97(25):13500-13505.

Djidjou-Demasse, R., Moury, B., and Fabre, F. (2017). Mosaics often outperform pyramids: insights from a model comparing strategies for the deployment of plant resistance genes against viruses in agricultural landscapes. New Phytologist, 216(1):239-253.

Durrant, W. E. and Dong, X. (2004). Systemic acquired resistance. Annu. Rev. Phytopathol., 42:185-209.

Fabre, F., Rousseau, E., Mailleret, L., and Moury, B. (2012). Durable strategies to deploy plant resistance in agricultural landscapes. New Phytologist, 193(4):10641075.

Fabre, F., Rousseau, E., Mailleret, L., and Moury, B. (2015). Epidemiological and evolutionary management of plant resistance: optimizing the deployment of cultivar mixtures in time and space in agricultural landscapes. Evolutionary Applications, 8(10):919-932. 
Finckh, M., Gacek, E., Goyeau, H., Lannou, C., Merz, U., Mundt, C., Munk, L., Nadziak, J., Newton, A., de Vallavieille-Pope, C., et al. (2000). Cereal variety and species mixtures in practice, with emphasis on disease resistance. Agronomie, 20:813837.

Flor, H. H. (1971). Current status of the gene-for-gene concept. Annual review of phytopathology, 9(1):275-296.

Fraile, A., Pagán, I., Anastasio, G., Sáez, E., and García-Arenal, F. (2010). Rapid genetic diversification and high fitness penalties associated with pathogenicity evolution in a plant virus. Molecular biology and evolution, 28(4):1425-1437.

Fu, Z. Q. and Dong, X. (2013). Systemic acquired resistance: turning local infection into global defense. Annual review of plant biology, 64:839-863.

Gandon, S., van Baalen, M., and Jansen, V. A. (2002). The evolution of parasite virulence, superinfection, and host resistance. The American Naturalist, 159(6):658669.

Garrett, K. and Mundt, C. (1999). Epidemiology in mixed host populations. Phytopathology, 89(11):984-990.

Groth, J. (1976). Multilines and "super races": a simple model. Phytopathology, 66(937):9.

Hamilton, W. D., Axelrod, R., and Tanese, R. (1990). Sexual reproduction as an adaptation to resist parasites (a review). Proceedings of the National Academy of Sciences, 87(9):3566-3573.

Han, G.-y., Jie, L., Yan, S., Wang, Y.-y., Zhu, Y.-y., and Lu, B.-r. (2016). Intercropping of rice varieties increases the efficiency of blast control through reduced disease occurrence and variability. Journal of integrative agriculture, 15(4):795-802.

Huang, Y.-J., Balesdent, M.-H., Li, Z.-Q., Evans, N., Rouxel, T., and Fitt, B. D. (2010). Fitness cost of virulence differs between the Avrlm1 and Avrlm4 loci in Leptosphaeria maculans (phoma stem canker of oilseed rape). European Journal of Plant Pathology, 126(2):279. 
Ishibashi, K., Mawatari, N., Miyashita, S., Kishino, H., Meshi, T., and Ishikawa, M. (2012). Coevolution and hierarchical interactions of Tomato mosaic virus and the resistance gene Tm-1. PLoS pathogens, 8(10):e1002975.

Janzac, B., Montarry, J., Palloix, A., Navaud, O., and Moury, B. (2010). A point mutation in the polymerase of Potato virus $Y$ confers virulence toward the Pvr4 resistance of pepper and a high competitiveness cost in susceptible cultivar. Molecular plant-microbe interactions, 23(6):823-830.

Jeger, M., Griffiths, E., and Jones, D. G. (1981a). Disease progress of non-specialised fungal pathogens in intraspecific mixed stands of cereal cultivars. I. models. Annals of Applied Biology, 98(2):187-198.

Jeger, M., Jones, D. G., and Griffiths, E. (1981b). Disease progress of non-specialised fungal pathogens in intraspecific mixed stands of cereal cultivars. II. field experiments. Annals of Applied Biology, 98(2):199-210.

Jenner, C. E., Wang, X., Ponz, F., and Walsh, J. A. (2002). A fitness cost for Turnip mosaic virus to overcome host resistance. Virus research, 86(1-2):1-6.

Kampmeijer, P. and Zadoks, J. (1977). Epimul, a simulator of foci and epidemics in mixtures, multilines, and mosaics of resistant and susceptible plants. Wageningen, Netherlands: PUDOC (Centre for agricultural publishing and documentation).

Khatabi, B., Wen, R.-H., and Hajimorad, M. (2013). Fitness penalty in susceptible host is associated with virulence of soybean mosaic virus on Rsv1-genotype soybean: a consequence of perturbation of HC-Pro and not P3. Molecular plant pathology, 14(9):885-897.

Kuć, J. (1982). Induced immunity to plant disease. Bioscience, 32(11):854-860.

Lannou, C., De Vallavieille-Pope, C., and Goyeau, H. (1995). Induced resistance in host mixtures and its effect on disease control in computer-simulated epidemics. Plant Pathology, 44(3):478-489.

Lannou, C., Hubert, P., and Gimeno, C. (2005). Competition and interactions among stripe rust pathotypes in wheat-cultivar mixtures. Plant Pathology, 54(5):699-712. 
Lannou, C. and Mundt, C. (1997). Evolution of a pathogen population in host mixtures: rate of emergence of complex races. Theoretical and applied genetics, 94(8):991-999.

Madden, L. V., Hughes, G., and Van Den Bosch, F. (2007). The study of plant disease epidemics. American Phytopathology Society.

Maleck, K., Levine, A., Eulgem, T., Morgan, A., Schmid, J., Lawton, K. A., Dangl, J. L., and Dietrich, R. A. (2000). The transcriptome of Arabidopsis thaliana during systemic acquired resistance. Nature genetics, 26(4):403.

Matthews, G. (2015). Pesticides: health, safety and the environment. John Wiley \& Sons.

Mikaberidze, A., McDonald, B. A., and Bonhoeffer, S. (2015). Developing smarter host mixtures to control plant disease. Plant Pathology, 64(4):996-1004.

Milgroom, M. G. (2015). Population biology of plant pathogens: genetics, ecology, and evolution. APS Press.

Mishina, T. E. and Zeier, J. (2007). Pathogen-associated molecular pattern recognition rather than development of tissue necrosis contributes to bacterial induction of systemic acquired resistance in arabidopsis. The Plant Journal, 50(3):500-513.

Montarry, J., Hamelin, F. M., Glais, I., Corbière, R., and Andrivon, D. (2010). Fitness costs associated with unnecessary virulence factors and life history traits: evolutionary insights from the potato late blight pathogen Phytophthora infestans. BMC Evolutionary Biology, 10(1):283.

Mundt, C. (2002). Use of multiline cultivars and cultivar mixtures for disease management. Annual review of phytopathology, 40(1):381-410.

Nilusmas, S., Mercat, M., Perrot, T., Djian-Caporalino, C., Castagnone-Sereno, P., Touzeau, S., Calcagno, V., and Mailleret, L. (2020). Multiseasonal modelling of plant-nematode interactions reveals efficient plant resistance deployment strategies. Evolutionary Applications.

Ohtsuki, A. and Sasaki, A. (2006). Epidemiology and disease-control under gene-forgene plant-pathogen interaction. Journal of theoretical biology, 238(4):780-794. 
Papaïx, J., Rimbaud, L., Burdon, J. J., Zhan, J., and Thrall, P. H. (2018). Differential impact of landscape-scale strategies for crop cultivar deployment on disease dynamics, resistance durability and long-term evolutionary control. Evolutionary applications, 11(5):705-717.

Pastor, V., Luna, E., Mauch-Mani, B., Ton, J., and Flors, V. (2013). Primed plants do not forget. Environmental and experimental botany, 94:46-56.

Poulicard, N., Pinel-Galzi, A., Hébrard, E., and Fargette, D. (2010). Why Rice yellow mottle virus, a rapidly evolving RNA plant virus, is not efficient at breaking rymv1-2 resistance. Molecular plant pathology, 11(1):145-154.

Reiss, E. R. and Drinkwater, L. E. (2018). Cultivar mixtures: a meta-analysis of the effect of intraspecific diversity on crop yield. Ecological applications, 28(1):62-77.

Rimbaud, L., Papaïx, J., Barrett, L. G., Burdon, J. J., and Thrall, P. H. (2018a). Mosaics, mixtures, rotations or pyramiding: What is the optimal strategy to deploy major gene resistance? Evolutionary Applications, 11(10):1791-1810.

Rimbaud, L., Papaïx, J., Rey, J.-F., Barrett, L. G., and Thrall, P. H. (2018b). Assessing the durability and efficiency of landscape-based strategies to deploy plant resistance to pathogens. PLoS computational biology, 14(4):e1006067.

Ross, A. F. (1961). Systemic acquired resistance induced by localized virus infections in plants. Virology, 14(3):340-358.

Rousseau, E., Bonneault, M., Fabre, F., Moury, B., Mailleret, L., and Grognard, F. (2019). Virus epidemics, plant-controlled population bottlenecks and the durability of plant resistance. Philosophical Transactions of the Royal Society $B$, 374(1775):20180263.

Sasaki, A. (2000). Host-parasite coevolution in a multilocus gene-for-gene system. Proceedings of the Royal Society of London. Series B: Biological Sciences, 267(1458):2183-2188.

Tellier, A. and Brown, J. K. (2007). Stability of genetic polymorphism in hostparasite interactions. Proceedings of the Royal Society B: Biological Sciences, 274(1611):809-817. 
Tellier, A. and Brown, J. K. (2008). The relationship of host-mediated induced resistance to polymorphism in gene-for-gene relationships. Phytopathology, 98(1):128136.

Tellier, A. and Brown, J. K. (2009). The influence of perenniality and seed banks on polymorphism in plant-parasite interactions. The American Naturalist, 174(6):769779.

Thrall, P. H. and Burdon, J. J. (2003). Evolution of virulence in a plant host-pathogen metapopulation. Science, 299(5613):1735-1737.

Tidbury, H. J., Best, A., and Boots, M. (2012). The epidemiological consequences of immune priming. Proceedings of the Royal Society B: Biological Sciences, 279(1746):4505-4512.

Vallad, G. E. and Goodman, R. M. (2004). Systemic acquired resistance and induced systemic resistance in conventional agriculture. Crop science, 44(6):1920-1934.

Vanderplank, J. E. (1968). Disease resistance in plants. Academic Press.

Verberne, M. C., Verpoorte, R., Bol, J. F., Mercado-Blanco, J., and Linthorst, H. J. (2000). Overproduction of salicylic acid in plants by bacterial transgenes enhances pathogen resistance. Nature biotechnology, 18(7):779.

Vlot, A. C., Klessig, D. F., and Park, S.-W. (2008). Systemic acquired resistance: the elusive signal(s). Current opinion in plant biology, 11(4):436-442.

Walters, D., Walsh, D., Newton, A., and Lyon, G. (2005). Induced resistance for plant disease control: maximizing the efficacy of resistance elicitors. Phytopathology, 95(12):1368-1373.

Watkinson-Powell, B., Gilligan, C., and Cunniffe, N. J. (2019). When does spatial diversification usefully maximise the durability of crop disease resistance? Phytopathology, (ja).

Wichmann, G. and Bergelson, J. (2004). Effector genes of Xanthamonas axonopodis pv. vesicatoria promote transmission and enhance other fitness traits in the field. Genetics, 166(2):693-706. 
Wolfe, M. (1985). The current status and prospects of multiline cultivars and variety mixtures for disease resistance. Annual review of phytopathology, 23(1):251-273.

Wolfe, M. S. and Ceccarelli, S. (2020). The increased use of diversity in cereal cropping requires more descriptive precision. Journal of the Science of Food and Agriculture, 100(11):4119-4123.

Xu, X. (2012). Super-races are not likely to dominate a fungal population within a life time of a perennial crop plantation of cultivar mixtures: a simulation study. BMC ecology, 12(1):16.

Zhan, J., Thrall, P. H., Papaïx, J., Xie, L., and Burdon, J. J. (2015). Playing on a pathogen's weakness: using evolution to guide sustainable plant disease control strategies. Annual review of phytopathology, 53:19-43.

Zhu, Y., Chen, H., Fan, J., Wang, Y., Li, Y., Chen, J., Fan, J., Yang, S., Hu, L., Leung, H., et al. (2000). Genetic diversity and disease control in rice. Nature, 406(6797):718.

Zivković, D., John, S., Verin, M., Stephan, W., Tellier, A., et al. (2019). Neutral genomic signatures of host-parasite coevolution. BMC Evolutionary Biology, 19(1):1-11. 


\begin{tabular}{|c|c|}
\hline Acronym & Definition \\
\hline WT & Wild-type \\
\hline RB & Resistance-breaking \\
\hline AUDPC & Area Under Disease Progress Curve \\
\hline Parameter & Definition \\
\hline$p$ & proportion of resistant hosts in the mixture: $p \in[0,1]$ \\
\hline$c$ & resistance-breaking cost: $c \in[0,1]$ \\
\hline$\rho$ & priming effect: $\rho \in[0,1]$ \\
\hline$\gamma$ & priming loss rate: $\gamma \geq 0$ \\
\hline$\alpha$ & harvest and replanting rate: $\alpha>0$ \\
\hline$\beta$ & pathogen transmission rate: $\beta>0$ \\
\hline$N$ & total host population density: $N>0$ \\
\hline$N_{r}$ & resistant host population density: $N_{r}=p N$ \\
\hline$N_{s}$ & susceptible host population density: $N_{s}=(1-p) N$ \\
\hline$R$ & basic reproduction number: $R=\beta N / \alpha>1$ \\
\hline$v$ & dimensionless parameter: $\nu=(\gamma+\alpha) / \alpha \geq 1$ \\
\hline Variable & Definition \\
\hline$t$ & time: $t \geq 0$ \\
\hline$I_{S}$ & density of WT-infected susceptible hosts \\
\hline$S_{r}^{*}$ & density of primed resistant hosts \\
\hline$J_{s}$ & density of RB-infected susceptible hosts \\
\hline$J_{r}$ & density of RB-infected resistant hosts \\
\hline$S_{S}$ & density of uninfected susceptible hosts: $S_{S}=N_{S}-I_{S}-J_{S}$ \\
\hline$S_{r}$ & density of uninfected resistant hosts: $S_{r}=N_{r}-S_{r}^{*}-J_{r}$ \\
\hline$F$ & force of infection of the WT genotype: $F=\beta I_{S}$ \\
\hline G & force of infection of the RB genotype: $G=(1-c) \beta\left(J_{s}+J_{r}\right)$ \\
\hline$x$ & proportion of WT-infected susceptible hosts: $x=I_{S} / N$ \\
\hline$m$ & proportion of primed resistant hosts: $m=S_{r}^{*} / N$ \\
\hline$y$ & proportion of RB-infected susceptible hosts: $y=J_{s} / N$ \\
\hline$z$ & proportion of RB-infected resistant hosts: $z=J_{r} / N$ \\
\hline$P$ & total prevalence of infected hosts: $P=\left(I_{s}+J_{s}+J_{r}\right) / N=x+y+z$ \\
\hline$P_{W T}$ & total prevalence at the WT-Only equilibrium: $P_{W T}=(1-p)-1 / R$ \\
\hline$P_{R B}$ & total prevalence at the RB-Only equilibrium: $P_{R B}=1-1 /[R(1-c)]$ \\
\hline$P_{C E}$ & total prevalence at the Coexistence equilibrium \\
\hline$P_{S}$ & total prevalence in susceptible hosts: $P_{s}=\left(I_{s}+J_{s}\right) / N_{s}=(x+y) /(1-p)$ \\
\hline $\operatorname{Pr}$ & total prevalence in resistant hosts: $P_{r}=J_{r} / N_{r}=z / p$ \\
\hline$P_{w}$ & prevalence of the WT genotype: $P_{w}=I_{S} / N=\chi$ \\
\hline$P_{b}$ & prevalence of the RB genotype: $P_{b}=\left(J_{s}+J_{r}\right) / N=y+z$ \\
\hline$A_{U D P C}$ & Area Under Disease Progress Curve: $A_{U D P C}(t)=\int_{0}^{t} P(\tau) \mathrm{d} \tau$ \\
\hline
\end{tabular}

Table 1 


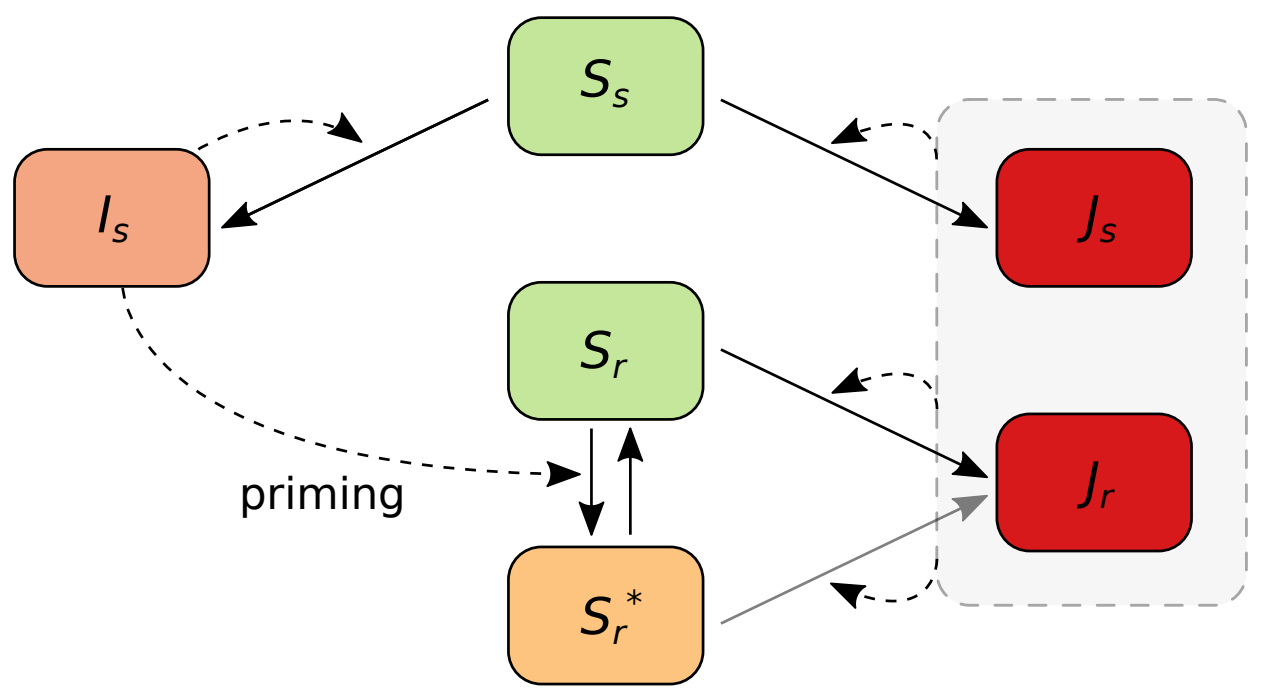

Figure 1: Simplified compartmental diagram for the epidemiological model described by equations (1). The model notations and their definitions are listed in Table 1.

\section{Figure 2}

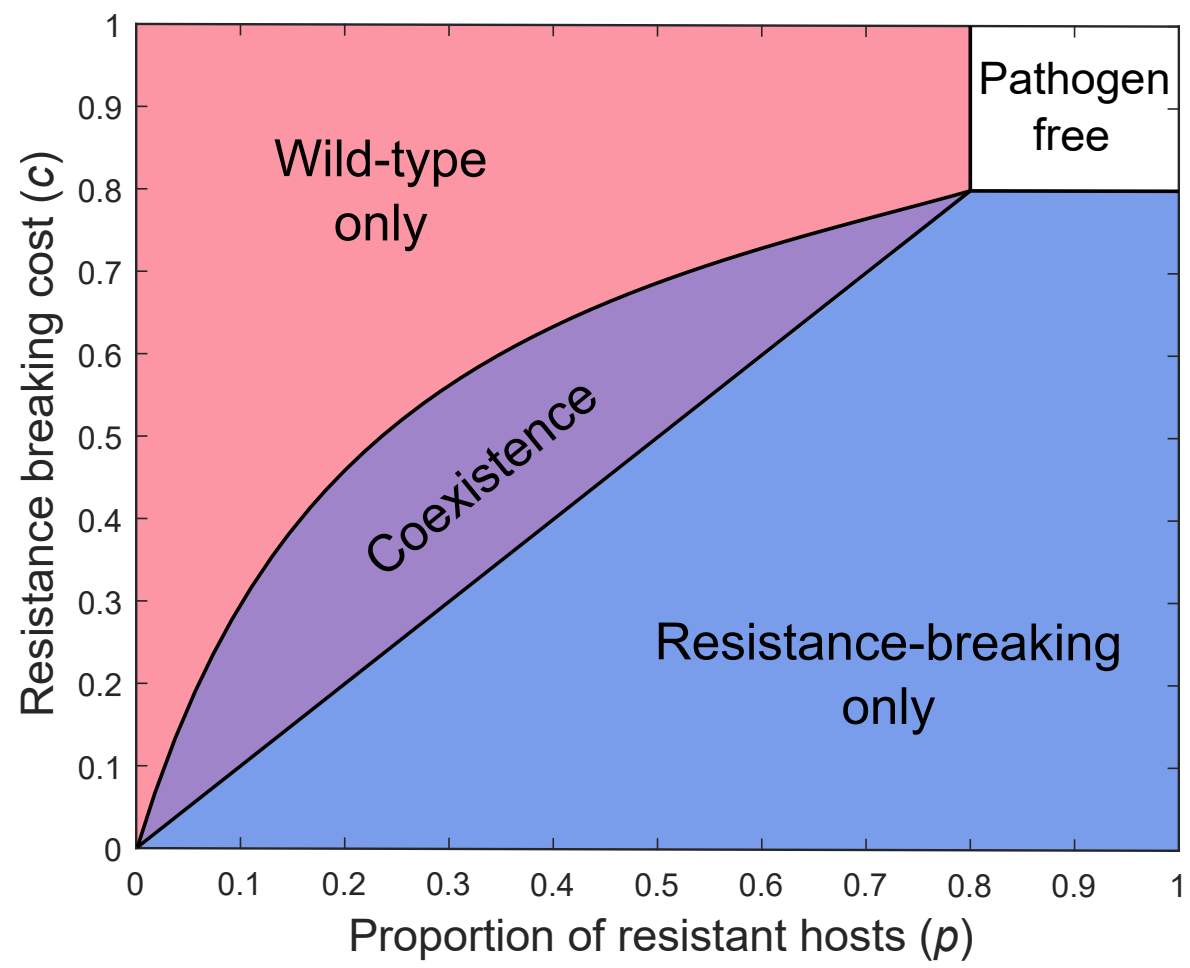

Figure 2: Epidemiological outcomes in the parameter space $(p, c)$. Other parameter values: $R=5$, $\rho=0.5$, and $\nu=1$. The model notations and their definitions are listed in Table 1 . 

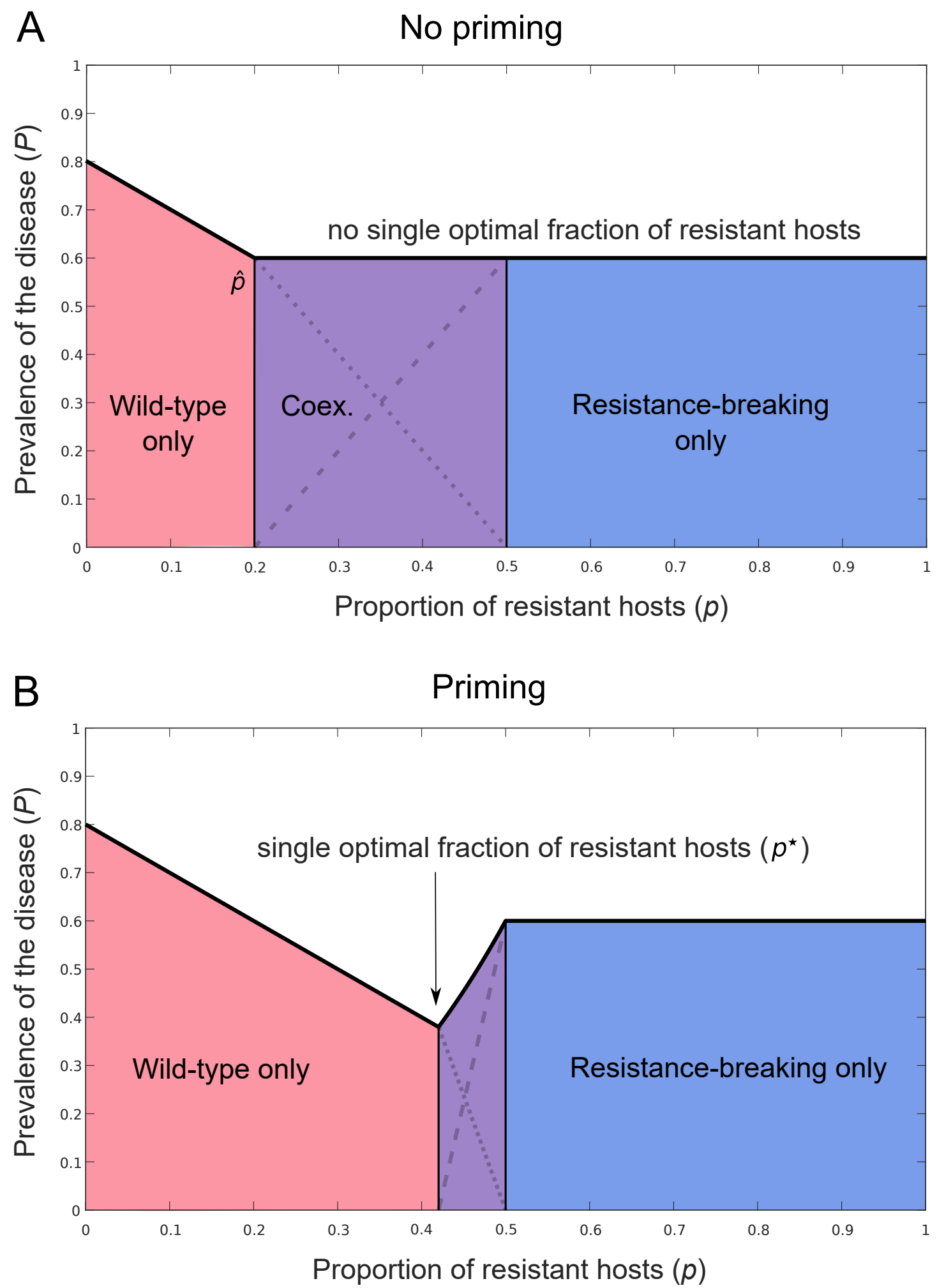

Figure 3: The total prevalence of the disease $(P)$ as a function of the proportion of resistant hosts $p$. Panel A shows the baseline without priming $(\rho=0)$ : all $p$ such that $\hat{p} \leq p \leq 1$ equally minimize the disease prevalence. Panel B shows the effect of priming $(\rho=0.8)$ : there is a single optimal fraction of resistant host $p^{\star}$. Other parameter values: $c=0.5, R=5$, and $v=1$. The model notations and their definitions are listed in Table 1 . The crossing lines in the coexistence region represent the prevalences of the WT ( $P_{w}$ : dotted line) and RB genotype ( $P_{b}$ : dashed line). 
A

no priming

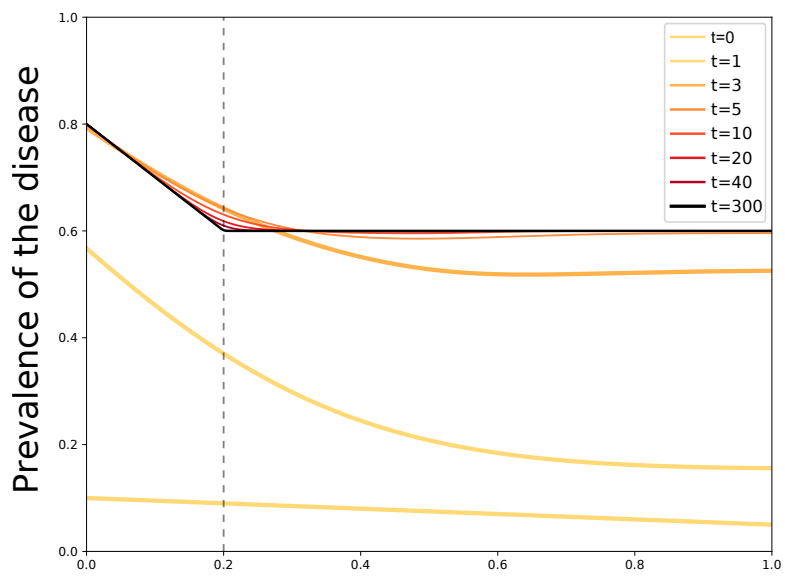

C

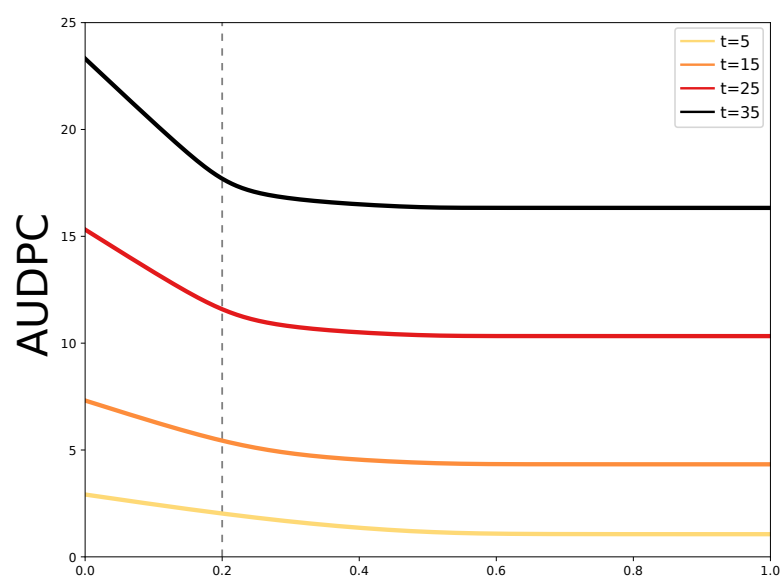

Proportion of resistant hosts $(p)$
B priming

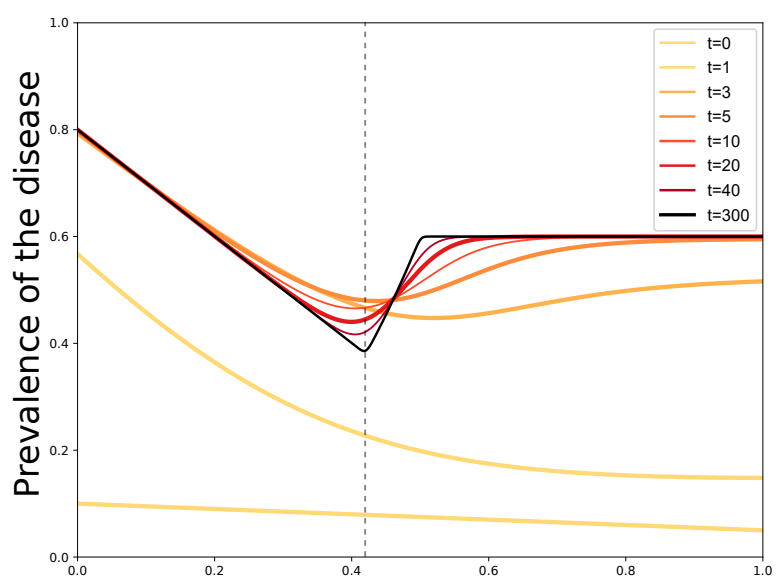

D

Proportion of resistant hosts $(p)$

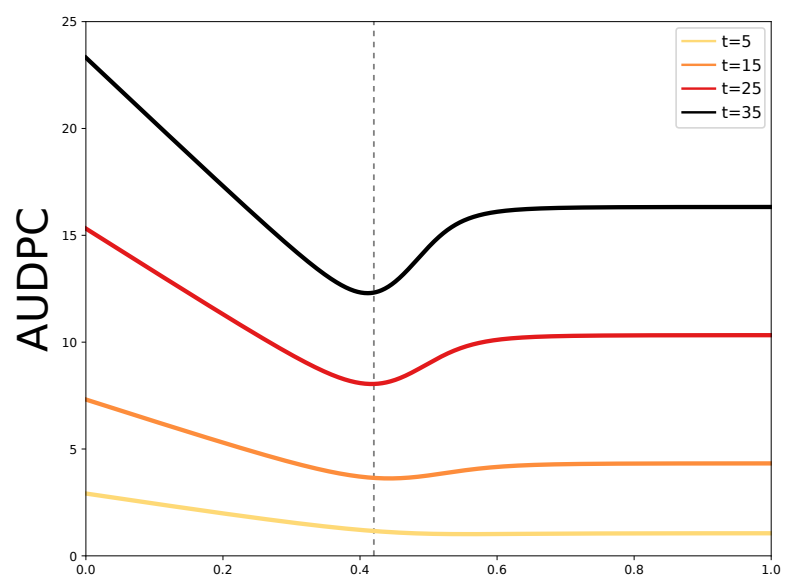

Proportion of resistant hosts $(p)$

Figure 4: Prevalence of the disease $(P)$ and Area Under the Disease Progress Curve (AUDPC) over time and as a function of $p$, without priming (left column: $\rho=0$ ) and with priming (right column: $\rho=0.8$ ). Other parameter values: $R=5, c=0.5$ and $\nu=1$. The initial conditions are $I_{S}=0.01(1-p) / 2$, $S_{r}^{*}=0.01 p / 2, J_{s}=0.01(1-p) / 2$ and $J_{r}=0.01 p / 2$. 
A No priming

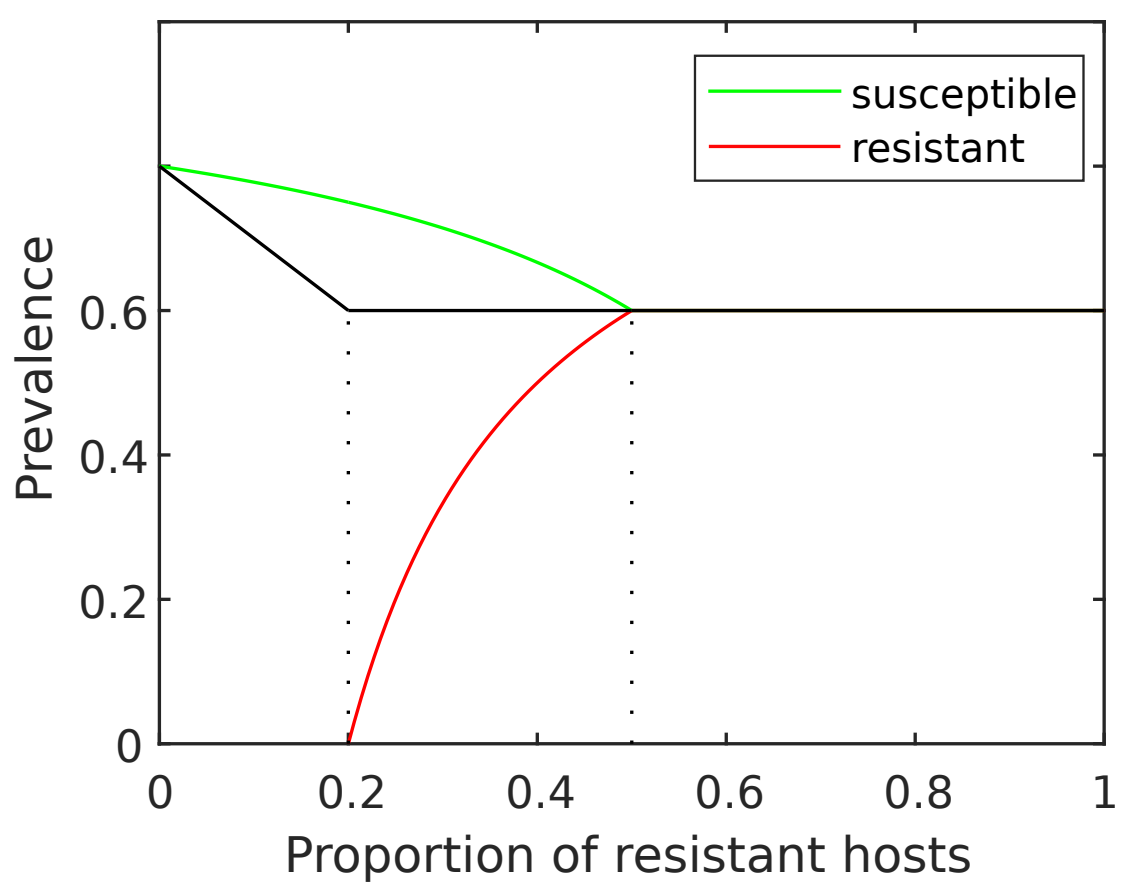

B Priming

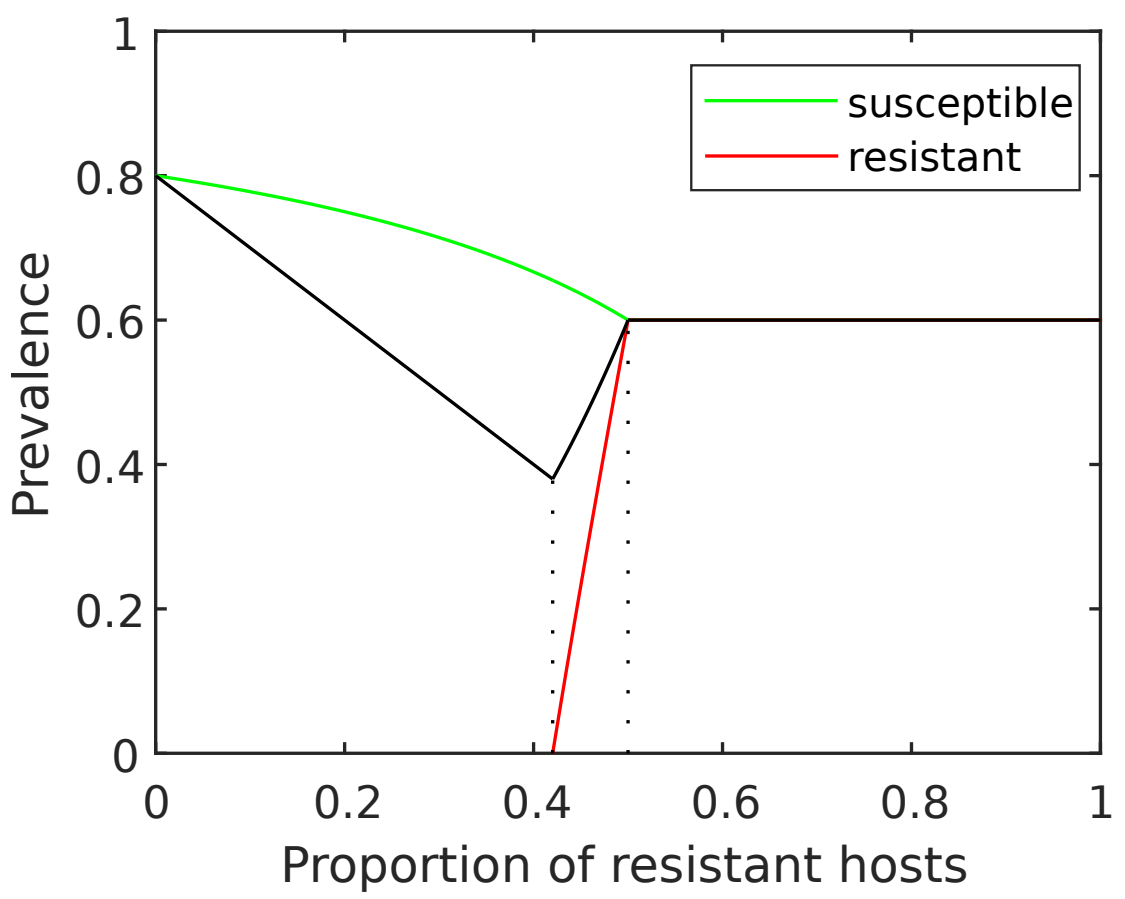

Figure 5: Prevalences in the host population as a function of the proportion of resistant hosts $(p)$. The black lines represent the total prevalence $(P)$. The green and red lines represent the prevalences in susceptible $\left(P_{S}\right)$ and resistant hosts $\left(P_{r}\right)$, respectively. The dotted vertical lines represent transitions from the WT-only, coexistence, and RB-only regions (Fig. 3). Panel A considers no priming $(\rho=0)$, and Panel B takes priming into account $(\rho=0.8)$. Other parameter values: $c=0.5, R=5$, and $v=1$. The model notations and their definitions are listed in Table 1. 